\title{
MEDA INEQUALITY FOR REARRANGEMENTS OF THE $B$-CONVOLUTIONS AND SOME APPLICATIONS
}

\author{
V. S. Guliyev, A. Serbetci and Z. V. Safarov
}

\begin{abstract}
In this paper we prove the Meda inequality for rearrangements of the convolution operator ( $B$-convolution) associated with the Laplace-Bessel differential operator. By using the Meda inequality for rearrangements we obtain an O'Neil type inequality for the $B$-convolution. As applications of these results, we obtain necessary and sufficient conditions on the parameters for the boundedness of the fractional $B$-maximal operator and $B$-fractional integral operator with rough kernels, from the spaces $L_{p, \gamma}$ to $L_{q, \gamma}$ and from the spaces $L_{1, \gamma}$ to the weak spaces $W L_{q, \gamma}$.
\end{abstract}

Mathematics subject classification (2000): 42B25, 42B35, 44A35.

Keywords and phrases: Laplace-Bessel differential operator, $B$-convolution, rearrangement of a function, meda inequality, O'Neil type inequality, $B$-fractional integral, fractional $B$-maximal function.

\section{REFERENCES}

[1] I. A. AlIEV, A. D. GADJIEV, On classes of operators of potential types, generated by a shift, Reports of enlarged Session of the Seminars of I. N. Vekua Inst. of Applied Mathematics, Tbilisi. 3 (1988), 2, 21-24 (Russian).

[2] A. D. GADJIEV AND V. S. GuLIYEV, The Stein-Weiss type inequality for fractional integrals, associated with the Laplace-Bessel differential operator, Fractional Calculus and Applied Analysis, vol. 11 (2008), No. 1, 77-90.

[3] V. S. GuLIYEv, Sobolev theorems for B-Riesz potentials, Dokl. Akad. Nauk., 358 (1998), 4, 450-451. (Russian)

[4] V. S. GuLIYEV, On maximal function and fractional integral, associated with the Bessel differential operator, Math. Inequal. Appl., 6 (2003), 2, 317-330.

[5] V. S. GULIYEV, A. SERBETCI AND I. EKINCIOGLU, Necessary and sufficient conditions for the boundedness of rough B-fractional integral operators in the Lorentz spaces, J. Math. Anal. Appl., 336 (2007) 425-437.

[6] V. S. GULIYEV, A. SERBETCI, Z. V. SAFAROV, Inequality of O'Neil-type for convolutions associated with the Laplace-Bessel differential operator and applications, Math. Inequal. Appl., 2008, vol. 11, no. 1, 99-112.

[7] D. E. Edmunds, W. D. Evans, Hardy operators, function spaces and embeddings, Springer Monographs in Mathematics, Springer-Verlag-Berlin Heidelberg, 2004.

[8] I. A. KIPRIJANOv, Fourier-Bessel transformations and imbedding theorems, Trudy Math. Inst. Steklov, 89 (1967), 130-213.

[9] L. N. LYAKHOV, Multipliers of the mixed Fourier-Bessel transformation, Proc. Steklov Inst. Math., 214 (1997), 234-249.

[10] S. MEDA, A Note on Fractional Integration, Rend. Sem. Mat. Univ. Pogova, 81(1989), 31-35.

[11] R. O'NeIL, Convolution operators and L(p,q) spaces, Duke Math. J., 30 (1963), 129-142.

[12] E. M. STEIN AND G. WeISS, Introduction to Fourier Analysis on Euclidean Spaces, Princeton Univ. Press, 1971. 